\title{
Prostaglandins and the Role of MRP-4 Transporters in their Fate
}

\author{
Malekinejad Hassan* \\ Department of Pharmacology \& Toxicology, School of Pharmacy, Urmia University of Medical Sciences, Urmia, Iran
}

*Corresponding author: Malekinejad Hassan, Department of Pharmacology \& Toxicology, School of Pharmacy, Urmia University

of Medical Sciences, Urmia, Iran

\begin{tabular}{|c|c|}
\hline ARTICLE INFO & ABSTRACT \\
\hline Received: 幽 June 18, 2019 & \multirow{2}{*}{$\begin{array}{l}\text { Citation: Malekinejad Hassan. Prostaglandins and the Role of MRP-4 Transporters in } \\
\text { their Fate. Biomed J Sci \& Tech Res 19(1)-2019. BJSTR. MS.ID.003249. }\end{array}$} \\
\hline Published: 幽 June 24, 2019 & \\
\hline
\end{tabular}

\section{Prostaglandins: Biosynthesis, Functions and Mechanism of Action}

Prostaglandins (PGs) are synthesized by cyclooxygenases (COX1, -2 and recently identified COX-3) from arachidonic acid after liberation of it by phospholipase $\mathrm{A} 2$ from membrane phospholipids and converted firstly into PGH2 and then into different end products of prostaglandins including PGE2, PGF2 $\alpha$. Their catabolism take place mostly by PG 15-dehydrogenase that oxidize them into biologically inactive metabolites such as 15-ketoPGE2 [1]. It has been documented that the type of PGs in various organs is tissuedependent as TXA2 is synthesized dominantly in the platelets, while PGI2 mostly is produced by the arterial wall, corpus luteum, follicle, and uterus and two others including PGE2 and PGF2a are produced in every organ [2]. Prostaglandins are involved in a large number of biological effects and their cellular actions are mediated by interaction of PGs with plasma membrane receptors. PG receptors belong to the superfamily of G-protein-coupled receptors with intracellular second messengers of cAMP, protein kinase $\mathrm{C}$, and calcium [3]. Of course some prostaglandins interact with the nuclear hormone receptor peroxisomal proliferator-activated receptor $\gamma$ [4].

PGs are not only important players in physiologic events such as renal and bronchial vasodilation, uterine smooth muscle relaxation and contraction and luteolysis, but also they do have crucial role in various pathologic conditions and disorders including: inflammation, pain, pyrexia, cardiovascular disease, renal disease, cancer, glaucoma, allergic rhinitis, asthma preterm labor, male sexual dysfunction and osteoporosis [5]. There are numerous reports showing downstream events following PGs binding to extracellular domain of PG receptors, however based on current evidence still there are missing facts to show how PG are released.

\section{Prostaglandins: Uptake and Release}

An early opinion believes that PGs are impermeable to cell membranes and cannot cross plasma membranes by simple diffusion. The main reason for this phenomenon is that PGs are organic anions with a Pka of 5 and therefore at physiological $\mathrm{pH}(\mathrm{pH}$ 7.4) they are as charged form [6]. Hence, to cross the cell membranes and consequently to bind the PG receptors for indigenously biosynthesized PGs, PGs need an aid of transporter systems (PG transporter). At the same time it is also believed that to launch the PGs degradation processes by 15-hydroxy PG dehydrogenase, the PGT-mediated uptake of PG from the extracellular environment is essentially needed [7]. During the last decades it has been explored that organic anion-transporting polypeptides (OATPs) are involved in transporting of PGs across the plasma membranes and among them OATP2A1/SLC02A1 has been recognized as a solute and high affinity carrier for PG transporter. These transporters are acting via an exchange mechanism, with lactate acting as the counter-ion and playing a major role in the PGs disposition in vivo and also in the febrile response $[8,9]$.The release of prostaglandins, a process essential for their physiologic and pathologic effects, has not been fully discussed.

Based on early studies, it has been reported that the efflux of cAMP is inhibited by prostaglandins, suggesting their competition for the same transporters. Later investigations revealed that not only cAMP but also cGMP efflux is inhibited by some prostaglandins, too [10]. Very recently it has been demonstrated that Multiple 
Drug Resistance-Associated Protein 4 (MRP4) along with PGT are important modulators of PGs signaling. Reid and co-workers (2003) as one of the leading research teams showed that MRP4 can release PGs from cells and even importantly inhibited from release of PGs by some nonsteroidal anti-inflammatory drugs [11]. In addition of previously mentioned indigenous compounds, MRP4 also functions in the absorption and secretion of drugs including antiviral, antibiotic, diuretic, antihypertensive, and cytotoxic agents, too [12]. This efflux transporter is expressed in wide range of tissues including in blood cells, smooth muscle cells, cardiomyocytes, bone cells, fibroblasts and cancer cells such as leukemia cell lines, lung cancer, pancreatic cancer and neuroblastoma and characterized by dual membrane localization [13].

The different membrane localization of MRP4 results in remarkable role in drug distribution and penetration. For instance, MRP4 localization at the brain blood barrier can prevent the penetration of oxins and xenobiotics into the brain. Accumulating evidence are indicating that the overexpression of MRP4 is one of the possible molecular mechanisms for failures of chemotherapy in certain tumors [14].

\section{Conclusion}

Taken all together, it is worth to direct some experimental studies to highlight the full role of PGT and MRP4 in the uptake and release of prostaglandins. It would be equally valuable to show how these transporter could be important therapeutic targets in various diseases, where PGs play crucial role in the pathogenesis of various diseases including cancers.

\section{References}

1. Tai HH, Ensor CM, Tong M, Zhou H, Yan F (2002) Prostaglandin catabolizing enzymes. Prostaglandins other lipid mediators (68-69): 483-493.

2. Watanabe $K$ (2011) Recent reports about enzymes related to the synthesis of prostaglandin $(\mathrm{PG}) \mathrm{F}_{2}\left(\mathrm{PGF}_{2 \alpha}\right.$ and $\left.9 \alpha, 11 \beta-\mathrm{PGF}_{2}\right)$. The Journal of Biochemistry 150(6): 593-596.

\section{ISSN: 2574-1241}

DOI: 10.26717/BJSTR.2019.19.003249

Malekinejad Hassan. Biomed J Sci \& Tech Res

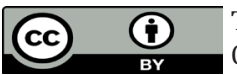

This work is licensed under Creative Commons Attribution 4.0 License

Submission Link: https://biomedres.us/submit-manuscript.php
3. Bos CL, Richel DJ, Ritsema T, Peppelenbosch MP, Versteeg HH (2004) Prostanoids and prostanoid receptors in signal transduction. The international journal of biochemistry \& cell biology 36(7): 1187-1205.

4. Harris SG, Padilla J, Koumas L, Ray D, Phipps RP (2002) Prostaglandins as modulators of immunity. Trends in immunology 23(3): 144-150.

5. Al Waili NS, Saloom KY, Al Waili T, Al Waili A, Al Waili H (2007) Modulation of prostaglandin activity, Part 1: Prostaglandin inhibition in the management of nonrheumatologic diseases: Immunologic and hematologic aspects. Advances in therapy 24(1): 189-222.

6. Bito LZ, Baroody RA (1975) Impermeability of rabbit erythrocytes to prostaglandins. American Journal of Physiology Legacy Content 229(6): 1580-1584.

7. Nomura T, Lu R, Pucci ML, Schuster VL (2004) The two-step model of prostaglandin signal termination: in vitro reconstitution with the prostaglandin transporter and prostaglandin 15 dehydrogenase. Molecular pharmacology 65(4): 973-978.

8. Nakanishi T, Tamai I (2018) Roles of organic anion transporting polypeptide $2 \mathrm{~A} 1\left(\mathrm{OATP}_{2} \mathrm{~A}_{1} / \mathrm{SLCO}_{2} \mathrm{~A}_{1}\right)$ in regulating the pathophysiological actions of prostaglandins. The AAPS journal 20(1): 13.

9. Chan BS, Endo S, Kanai N, Schuster VL (2002) Identification of lactate as a driving force for prostanoid transport by prostaglandin transporter PGT. American Journal of Physiology Renal Physiology 282(6): F1097-F102.

10. Wielinga PR, Van der Heijden I, Reid G, Beijnen JH, Wijnholds J, et al. (2003) Characterization of the MRP4-and MRP5-mediated transport of cyclic nucleotides from intact cells. Journal of Biological Chemistry 278(20): 17664-17671.

11. Reid G, Wielinga P, Zelcer N, van der Heijden I, Kuil A, et al. (2003) The human multidrug resistance protein MRP4 functions as a prostaglandin efflux transporter and is inhibited by nonsteroidal antiinflammatory drugs. Proceedings of the National Academy of Sciences 100(16): 92449249.

12. Wen J, Luo J, Huang W, Tang J, Zhou H, et al. (2015) The pharmacological and physiological role of Multidrug-Resistant Protein 4. The Journal of Pharmacology and Experimental Therapeutics 354(3): 358-375.

13. Berthier J, Arnion H, Saint Marcoux F, Picard N (2019) Multidrug resistance-associated protein 4 in pharmacology: Overview of its contribution to pharmacokinetics, pharmacodynamics and pharmacogenetics. Life Sciences 19: 30460-30466.

14. Oprea Lager DE, Bijnsdorp IV, Van Moorselaar RJ, Van den Eertwegh AJ, Hoekstra OS, et al. (2013) ABCC4 Decreases docetaxel and not cabazitaxel efficacy in prostate cancer cells in vitro. Anticancer research 33(2): 387-391.

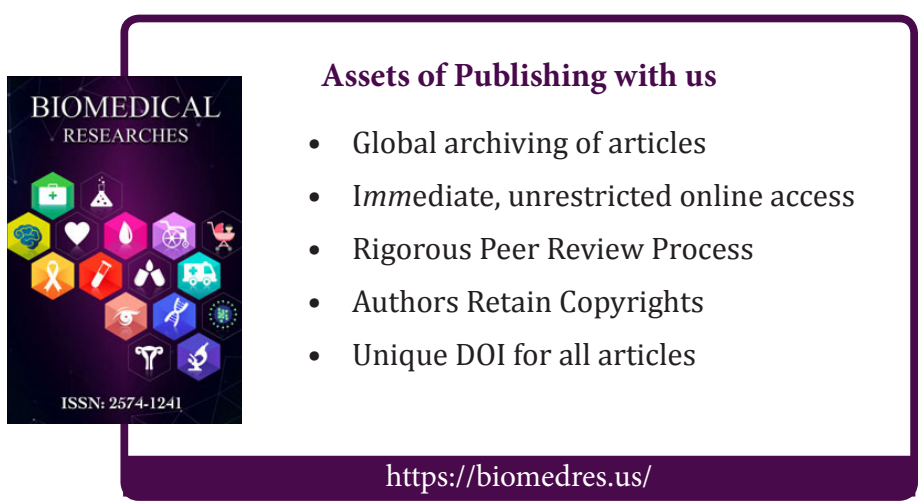

